\title{
The Biodegradation of Diethanolamine and Triethanolamine by a Yellow Gram-negative Rod
}

\author{
By G. R. WILliamS† AND A. G. CALLELY* \\ Department of Microbiology, University College, Newport Road, Cardiff CF2 1TA, U.K.
}

(Received 10 April 1981; revised 14 September 1981)

\begin{abstract}
A yellow Gram-negative rod-shaped organism that could grow with ethanolamine, diethanolamine or triethanolamine as the sole source of carbon and energy was isolated from a laboratory-scale activated-sludge plant. Studies with whole cells and cell-free extracts have enabled the inducible pathways for the degradation of these compounds to be elucidated. Triethanolamine is converted, via triethanolamine $N$-oxide, into diethanolamine and glycolaldehyde; diethanolamine in turn is converted into ethanolamine and glycolaldehyde. Ethanolamine is converted into acetyl units via ethanolamine $O$-phosphate and acetaldehyde. In di- and triethanolamine-grown cells the specific activities of glyoxylate carboligase and tartronic-semialdehyde reductase are comparatively high whilst that of isocitrate lyase is low; this situation is reversed in ethanolamine-grown cells. Triethanolamine- $N$-oxide dehydroxyethylase appears to be a product-induced enzyme and an inducible transport system may be involved in the uptake of diethanolamine.
\end{abstract}

\section{INTRODUCTION}

Use is made of amino alcohols, especially diethanolamine [2,2'-iminodiethanol, $\left.\mathrm{HN}\left(\mathrm{CH}_{2} \mathrm{CH}_{2} \mathrm{OH}\right)_{2}\right]$ and triethanolamine $\left[2,2^{\prime}, 2^{\prime \prime}\right.$-nitrilotriethanol, $\left.\mathrm{N}\left(\mathrm{CH}_{2} \mathrm{CH}_{2} \mathrm{OH}\right)_{3}\right]$, in cosmetic and pharmaceutical preparations, cutting fluids and polishes. All such formulations are subject to microbial infection as many of their components are biodegradable, though little is known about the catabolism of di- and triethanolamine. There is, however, far more information available about ethanolamine. It is a well-documented component of some bacterial lipopolysaccharides and phospholipids and many bacteria can use it either as a source of both carbon and nitrogen or just as a nitrogen source (Blackwell et al., 1976). The various routes described for the bacterial catabolism of ethanolamine involve ethanolamine ammonia-lyase (Bradbeer, 1965; Scarlett \& Turner, 1976), ethanolamine oxidase (Narrod \& Jakoby, 1964) or ethanolamine kinase (Jones \& Turner, 1971).

Though di- and triethanolamine have received little attention, the catabolism of unsubstituted secondary and tertiary amines and also nitrilotriacetic acid, the acid corresponding to triethanolamine, has been extensively studied. In one pathway, trimethylamine is converted to trimethylamine $N$-oxide which is demethylated to formaldehyde and dimethylamine (Large, 1971; Myers \& Zatman, 1971). The secondary amine is further oxidized to give formaldehyde and methylamine (Eady et al., 1971); a similar enzyme was found in the bacterium studied by Colby \& Zatman $(1973,1974)$. An analogous route accounted for the catabolism of nitrilotriacetic acid by a pseudomonad (Cripps \& Noble, 1973). Trimethylamine can be directly demethylated to dimethylamine and formaldehyde, this reaction being catalysed by trimethylamine dehydrogenase (Colby \&

\footnotetext{
† Present address: Biodeterioration Laboratory, Ministry of Defence Materials Quality Assurance Directorate, Royal Arsenal East, Woolwich, London SE18 6TD, U.K.
} 
Zatman, 1971). A dimethylamine dehydrogenase, whose activity and synthesis are affected by changes in oxygen tension, has been demonstrated in a hyphomicrobium (Meiberg \& Harder, 1979; Meiberg et al., 1980).

This paper, based on part of an extensive study of the biodegradation of the components of cutting fluids, describes the isolation of a microbe that can utilize, as growth substrates, mono-, di- and triethanolamine and how it catabolizes these compounds.

\section{METHODS}

Isolation, growth media, and maintenance of the organism. The organism was isolated in pure culture, by the enrichment culture technique, from sludge taken from a laboratory-scale activated-sludge plant treating an effluent containing cutting fluids. The bacterium - a yellow, Gram-negative, motile, rod-shaped organism - was cultured in a liquid medium containing $\left(\mathrm{g} \mathrm{l}^{-1}\right.$ in distilled water): carbon source, $1.0 ; \mathrm{KH}_{2} \mathrm{PO}_{4}, 2 \cdot 0 ;\left(\mathrm{NH}_{4}\right)_{2} \mathrm{SO}_{4}, 1 \cdot 0$; $\mathrm{MgSO}_{4} .7 \mathrm{H}_{2} \mathrm{O}, 0.04 ; \mathrm{FeCl}_{3} .6 \mathrm{H}_{2} \mathrm{O}, 0.04$. The $\mathrm{pH}$ was adjusted to 7.0 with $\mathrm{NaOH}$ before sterilization by autoclaving $\left(15 \mathrm{~min}, 120^{\circ} \mathrm{C}\right)$; the $\mathrm{Mg}$ and $\mathrm{Fe}$ salt solutions, both $10 \%(\mathrm{w} / \mathrm{v})$, were sterilized separately and the required volumes were added aseptically to the sterile solution of the other ingredients after cooling. The organism was maintained on solid medium prepared by adding $1.5 \%(\mathrm{w} / \mathrm{v})$ Difco Noble agar to the above medium with triethanolamine as the carbon source.

Growth and harvesting of cultures. Cultures $(100 \mathrm{ml})$ were grown, from a $10 \%$ inoculum of bacteria grown with the same carbon source, in $500 \mathrm{ml}$ conical flasks shaken $\left(200 \mathrm{rev}\right.$. $\left.\mathrm{min}^{-1}\right)$ at $30^{\circ} \mathrm{C}$ in an orbital incubator. Larger batches (1 I) were grown similarly in 31 flasks. Organisms in the late-exponential phase of growth were harvested by centrifugation at $10000 \mathrm{~g}$ for $15 \mathrm{~min}$ at $4{ }^{\circ} \mathrm{C}$; before use they were washed twice in distilled water.

Manometric experiments. These were carried out in a Gilson Differential Respirometer (Gilson Medical Electronics, Villiers-le-Bel, France). Measurements of $\mathrm{O}_{2}$ uptake by washed whole-cell suspensions were performed at $30^{\circ} \mathrm{C}$ in air. Reaction flasks contained (in a final volume of $3 \mathrm{ml}$ ) substrate, $15 \mu \mathrm{mol}$ phosphate buffer $(\mathrm{pH} 7 \cdot 0$ ), about $5 \mathrm{mg}$ dry wt cells and sometimes chloramphenicol $\left(200 \mu \mathrm{g} \mathrm{ml}^{-1}\right)$; centre wells contained $0.1 \mathrm{ml} 20 \%(\mathrm{w} / \mathrm{v})$ $\mathrm{KOH}$ and a small piece of fluted filter paper. In the glyoxylate carboligase assay, total $\mathrm{CO}_{2}$ production was measured by using reaction flasks fitted with two side-bulbs one of which contained $0.75 \mathrm{ml} 5 \mathrm{M}-\mathrm{H}_{2} \mathrm{SO}_{4}$; at a known time this was tipped into the reaction mixture to stop any further reaction and to liberate dissolved $\mathrm{CO}_{2}$.

Isolation of a volatile aldehyde formed during growth. This was carried out in an apparatus similar to that described by Dagley \& Gibson (1965) and Jones \& Turner (1973). The method involved pumping, for $48 \mathrm{~h}$, an air-stream through an otherwise sealed culture vessel at $30^{\circ} \mathrm{C}$ and then through foam and condensation traps into two Dreschel bottles containing 2,4-dinitrophenylhydrazine $(0 \cdot 1 \%, \mathrm{w} / \mathrm{v}$, solution in $2 \mathrm{M}-\mathrm{HCl})$. The air-stream had been bubbled through 2,4-dinitrophenylhydrazine solution and passed through a bacteriological filter before entering the vessel containing the growing culture. A yellow precipitate produced in the Dreschel bottles was collected by filtration, washed well with distilled water and dried at $105^{\circ} \mathrm{C}$.

Thin-layer chromatography (t.l.c.) of aldehyde-2,4-dinitrophenylhydrazones. This was carried out as described by Byrne (1965).

Preparation of cell-free extracts. Washed organisms from 31 of culture were suspended in $15-20 \mathrm{ml}$ $15 \mathrm{~mm}$-phosphate buffer ( $\mathrm{pH} 7.2)$ using a hand homogenizer. They were disrupted, at $0^{\circ} \mathrm{C}$, during three $30 \mathrm{~s}$ periods each separated by a 2 min cooling period, in an MSE 500 ultrasonic disintegrator fitted with a small probe. Unbroken bacteria were removed by centrifuging $\left(4^{\circ} \mathrm{C}, 7600 \mathrm{~g}, 15 \mathrm{~min}\right)$; the supernatant was used in the various enzyme assays.

Enzyme assays. All spectrophotometric assays were carried out in a Pye Unicam SP1800 recording spectrophotometer at room temperature; no attempt was made to find optimal conditions. Initial reaction rates were measured in order to calculate specific activities.

For measurement of the activity of the triethanolamine oxidase system, the reaction mixture contained (in a final volume of $3 \mathrm{ml}$ ) $10 \mu \mathrm{mol}$ phosphate buffer $(\mathrm{pH} 6 \cdot 8), 1 \mu \mathrm{mol} \mathrm{NADH}, 3 \mu \mathrm{mol}$ triethanolamine and extract; control cuvettes lacked substrate. The reaction was started by the addition of extract and the change in absorbance at $340 \mathrm{~nm}$ was followed. The assay system for diethanolamine oxidase was similar except for the different substrate and the buffer used which was $66.6 \mathrm{mM}-\mathrm{N}, \mathrm{N}$-bis(2-hydroxyethyl)-2-aminoethanesulphonic acid (BES) (pH 7.0). Triethanolamine- $N$-oxide dehydroxyethylase activity was determined by incubating extract with $100 \mu$ mol maleate buffer (pH 6.0) and $10 \mu \mathrm{mol}$ triethanolamine $N$-oxide. The final volume was $3 \mathrm{ml}$; controls lacked either extract or substrate. The reaction was stopped at known times by adding $0.5 \mathrm{ml} 0.4 \%(\mathrm{w} / \mathrm{v}) 3$-methyl-2-benzothiazolinone hydrazone in $0.1 \mathrm{M}-3,3$-dimethylglutaric acid/NaOH buffer ( $\mathrm{pH} 4.0$ ), and the amount of glycolaldehyde produced was determined.

Ethanolamine deaminase was assayed as described by Kaplan \& Stadtman (1971), ATP : ethanolamine phosphotransferase (EC 2.7.1.82) by the first of the two methods used by Jones \& Turner (1973) and 
ethanolamine- $O$-phosphate phospho-lyase (EC 4.2.99.7) by their spectrophotometric method. Aldehyde dehydrogenase (EC 1.2.1.3) activity was followed at $340 \mathrm{~nm}$ in a mixture that contained (in a final volume of $3 \mathrm{ml}) 100 \mu \mathrm{mol}$ Tris buffer $(\mathrm{pH} 8.5), 2 \mu \mathrm{mol} \mathrm{NAD}{ }^{+}, 10 \mu \mathrm{mol}$ glycolaldehyde or acetaldehyde and extract. Glyoxylate carboligase (EC 4.1.1.47) (Krakow \& Barkulis, 1956) was assayed by measuring the rate of anaerobic evolution of $\mathrm{CO}_{2}$ from glyoxylate; manometric flasks contained (in a final volume of $3 \mathrm{ml}$ ) $200 \mu \mathrm{mol}$ BES buffer ( $\mathrm{pH} 7.8$ ), $2.5 \mu \mathrm{mol}$ sodium glyoxylate and extract; control flasks lacked substrate. The system was purged with $\mathrm{N}_{2}$ before the start of the experiment, and the reaction was stopped and $\mathrm{CO}_{2}$ liberated by adding acid. Tartronic-semialdehyde reductase (EC 1.1.1.60) (Gotto \& Kornberg, 1961) was assayed (in a final volume of $3 \mathrm{ml}$ ) by following the disappearance of NADH $(1 \mu \mathrm{mol})$ at $340 \mathrm{~nm}$, in $200 \mu \mathrm{mol}$ phosphate buffer (pH 7.2) in the presence of substrate produced enzymically from $10 \mu \mathrm{mol}$ sodium glyoxylate before addition of NADH. Isocitrate lyase (EC 4.1.3.1) was measured by the method of Dixon \& Kornberg (1959) except that $200 \mu \mathrm{mol}$ BES buffer (pH 7.0) was used instead of phosphate buffer ( $\mathrm{pH} \mathrm{6.8).}$

Analytical methods and chemicals. Protein was estimated by the Lowry method using bovine serum albumin as the standard. Aldehydes were determined colorimetrically using 3-methyl-2-benzothiazolinone hydrazone (Paz et $a l ., 1965)$. The enzymes used in the coupling reactions in some of the enzyme assays, and various biochemicals were obtained from Sigma. Triethanolamine $N$-oxide was kindly supplied by Shell Research Ltd, Thornton Research Centre, U.K. All other chemicals were obtained from BDH and were the purest grade available.

\section{RES ULTS}

\section{Growth and whole-cell studies}

Good growth of the organism occurred with mono-, di- or triethanolamine as the sole source of carbon and energy. There was no significant growth of the organism during a period of $7 \mathrm{~d}$ with, for example, succinate as the major carbon source and any of the three amino alcohols as the sole nitrogen source; no further experiments were carried out in media of this type.

Cultures of the organism with any of the three ethanolamines, but especially with monoethanolamine, had a distinctive odour reminiscent of acetaldehyde, a known intermediate in ethanolamine degradation by some bacteria. The volatile compounds could be readily removed from cultures by bubbling a stream of sterile air through them and then into 2,4-dinitrophenylhydrazine in which a yellow precipitate was formed. These 2,4dinitrophenylhydrazones, together with those of authentic acetaldehyde, formaldehyde, glycolaldehyde, propionaldehyde, lactaldehyde, glyceraldehyde and acetone, ran as single discrete spots when examined by t.l.c. The unknown derivatives obtained from the mono-, dior triethanolamine cultures behaved identically; when mixed with authentic acetaldehyde2,4-dinitrophenylhydrazone the mixture $\operatorname{ran}$ as a single spot, indicating that the volatile compound produced in each culture was acetaldehyde. Most acetaldehyde was produced in the ethanolamine cultures, where it accumulated during the early stages of growth and then progressively disappeared.

Organisms, when examined manometrically, readily oxidized the substrates with which they had been grown. Thus, ethanolamine-grown organisms consumed $1.35 \mu \mathrm{mol} \mathrm{O}_{2}$ per mol ethanolamine initially present; the corresponding values for di- and triethanolamine-grown organisms oxidizing their respective growth substrates were 3.35 and 5.78 . These values account for $54 \%, 67 \%$ and $77 \%$, respectively, of the theoretical amounts of $\mathrm{O}_{2}$ needed for the complete oxidation of mono-, di- and triethanolamine to $\mathrm{CO}_{2}$, ammonia and water.

Organisms grown separately with each of the three ethanolamines were tested for the ability to oxidize triethanolamine, triethanolamine $\mathrm{N}$-oxide, diethanolamine, ethanolamine, ethanolamine $O$-phosphate, acetaldehyde and glycolaldehyde. Typical results are shown in Fig. 1. Ethanolamine-grown cells oxidized glycolaldehyde, di- and triethanolamine and triethanolamine $N$-oxide only after a lag, and no oxidation of these compounds occurred if chloramphenicol was present. Such cells after becoming induced to, and oxidizing, di- and triethanolamine could immediately oxidize glycolaldehyde without any lag period (Fig. 1 a).

Diethanolamine-grown cells oxidized triethanolamine $\mathrm{N}$-oxide immediately though only slowly; triethanolamine was oxidized only after a lag period and no oxidation of this substrate 

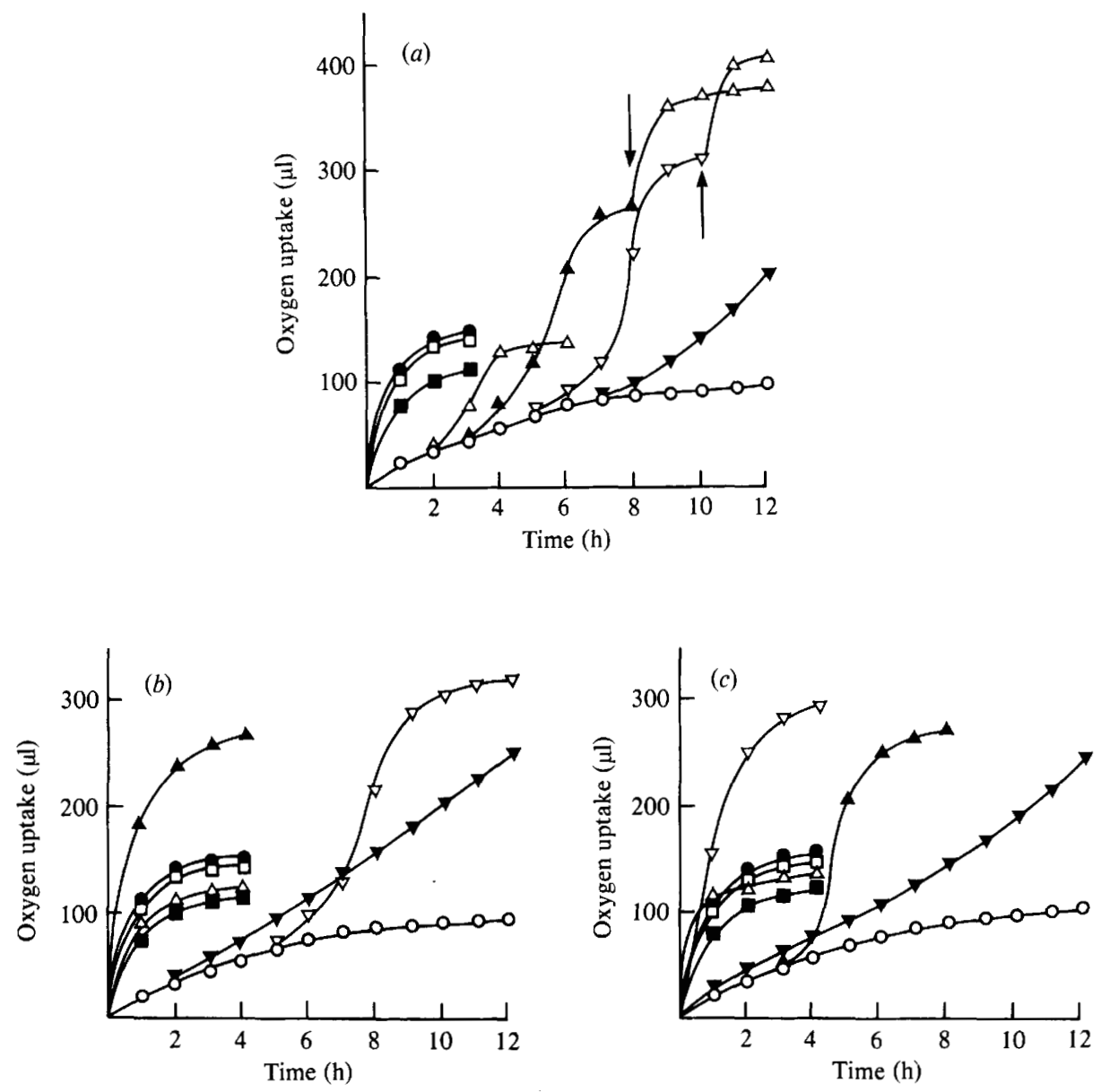

Fig. 1. Oxidation of various compounds $(2 \mu \mathrm{mol})$ by intact washed cells grown with $(a)$ ethanolamine, (b) diethanolamine and $(c)$ triethanolamine. Endogenous respiration, $O$; ethanolamine $O$-phosphate, $\bigcirc$; ethanolamine, $\square$; acetaldehyde, $\mathbf{\square}$; glycolaldehyde, $\Delta$; diethanolamine, $\Delta$; triethanolamine, $\nabla$; triethanolamine $N$-oxide, $\nabla$. Arrows in $(a)$ indicate when $2 \mu$ mol glycolaldehyde was added to reaction mixtures containing cells that had been oxidizing diethanolamine or triethanolamine.

occurred if chloramphenicol was present. Triethanolamine-grown cells readily oxidized all substrates except diethanolamine, which was rapidly oxidized only after a lag and not at all if chloramphenicol was present.

\section{Enzyme activities in cell-free extracts}

The whole-cell studies indicated that triethanolamine, triethanolamine $N$-oxide, glycolaldehyde, ethanolamine, ethanolamine $O$-phosphate and acetaldehyde are possible intermediates in the catabolism of triethanolamine; that all but the first two compounds could be involved in diethanolamine catabolism; and that ethanolamine is likely to be metabolized by the $O$-phosphate and acetaldehyde. Extracts of the organism grown with either mono-, di- or triethanolamine were examined for the presence and amount of enzymes likely to be involved in the interconversion and further metabolism of these compounds, and their specific activities were compared with those of the same enzymes assayed in extracts of succinate-grown cells. The results are summarized in Table 1. 
Table 1. Specific activities of enzymes likely to be involved in the catabolism of mono-, diand triethanolamine

\begin{abstract}
Bacteria were grown with succinate, mono-, di- or triethanolamine as the sole source of carbon and energy. After growth, extracts of washed bacteria were prepared and assayed for the enzymes listed below. The specific activities given are the average of several determinations using different crude extracts.
\end{abstract}

\begin{tabular}{|c|c|c|c|}
\hline & Specific & tivity $\left[\mathrm{nmol} \min ^{-1}(\mathrm{mg} \text { protein })^{-1}\right.$ & \\
\hline & & Organism grown with: & \\
\hline Enzyme & Triethanolamine & Diethanolamine Ethanolamine & Succinate \\
\hline
\end{tabular}

Triethanolamine oxidase

Triethanolamine- $N$-oxide dehydroxyethylase

Diethanolamine oxidase

ATP : ethanolamine phosphotransferase

Ethanolamine- $O$-phosphate phospho-lyase

Ethanolamine deaminase

Acetaldehyde dehydrogenase

Glycolaldehyde dehydrogenase

Glyoxylate carboligase

Tartronic-semialdehyde reductase

Isocitrate lyase

$\begin{array}{rrrr}65 & 4 & 0 & 0 \\ 65 & 68 & 3 & 2 \\ 67 & 73 & 7 & 5 \\ 60 & 56 & 87 & 0 \\ 48 & 50 & 64 & 0 \\ 0 & 0 & 0 & 0 \\ 30 & 30 & 45 & 0 \\ 40 & 25 & 0 & 0 \\ 95 & 75 & 0 & \text { NT } \\ 40 & 35 & 5 & \text { NT } \\ 3 & 11 & 60 & 4\end{array}$

NT, Not tested; 0 , not detected by assay method used.

\title{
DISCUSSION
}

The organism used in this study was one of several isolated from sludge taken from a laboratory-scale activated-sludge plant treating cutting fluids, one of which contained diethanolamine. The organism, isolated using diethanolamine, was chosen for further study because it grew the fastest and could also use triethanolamine and ethanolamine as growth substrates. The enzymes uniquely involved in the catabolism of the three ethanolamines are inducible; the inability of the organism to grow with succinate and any one of the three ethanolamines as the sole source of nitrogen could indicate that the catabolism of these nitrogenous compounds by the organism is subject to strong catabolite repression. This situation is similar to that, for example, in Escherichia coli OR 75 which grows very poorly in a medium with glucose and proline as the sole nitrogen source (Newman \& Cole, 1977) though it is capable of using proline as a sole source of energy, carbon and nitrogen.

All the data obtained are consistent with the proposed pathway, shown in Fig. 2, for the catabolism of the three ethanolamines. Positive evidence was obtained for the presence of all the reactions indicated with the exception of the conversion of glycollate to glyoxylate and of glycerate to pyruvate which were not investigated; hence it is not possible to completely rule out the possible involvement of glyoxal, either as an intermediate between glycolaldehyde and glycollate or instead of glycollate. Ethanolamine is catabolized solely to acetyl units via ethanolamine $O$-phosphate and acetaldehyde; no ethanolamine deaminase activity could be found. As acetyl units were the sole product of this metabolic sequence the high isocitrate lyase activity in extracts of ethanolamine-grown cells was predictable. However, in cells grown with diethanolamine and triethanolamine another sequence involving $C_{2}$ compounds is operative in addition to that from ethanolamine; there was a very significant increase in the amount of the two enzymes responsible for converting glyoxylate to glycerate from which other $\mathrm{C}_{3}$ compounds, such as phosphoenolpyruvate and pyruvate, known precursors of $\mathrm{C}_{4}$ compounds in other micro-organisms, would be produced. Thus, in cells grown with di- and triethanolamine a functional glyoxylate cycle is not necessary, and this was borne out by the amount of isocitrate lyase detected, which fell towards the value found in succinate-grown cells. 


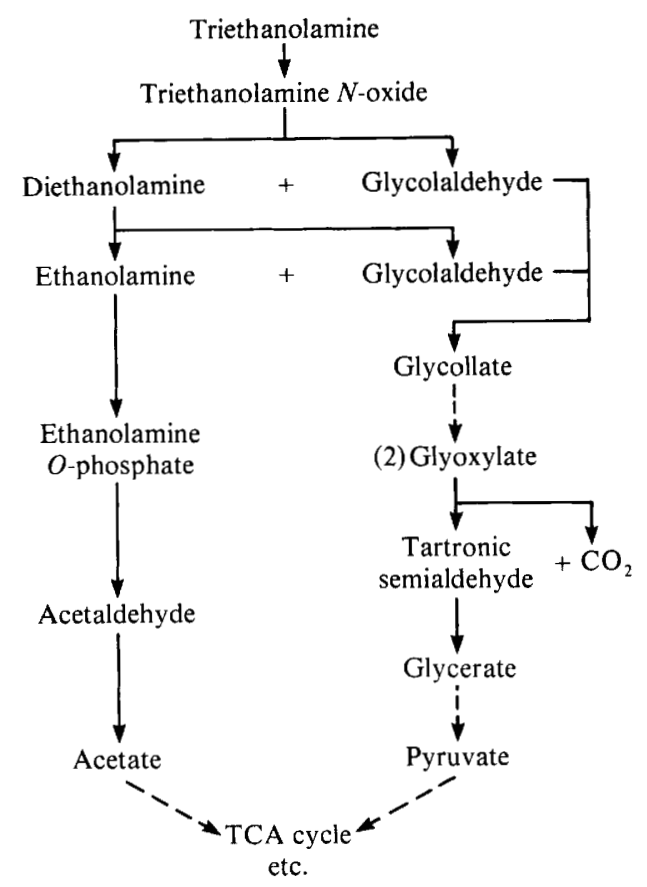

Fig. 2. Proposed pathway for the metabolism of triethanolamine, diethanolamine and ethanolamine by the yellow Gram-negative rod used in this study.

The rate of oxidation of triethanolamine $\mathrm{N}$-oxide by intact triethanolamine-grown cells was always lower than that of the growth substrate and those of the metabolites tested. This could be due to the inability of intact cells to rapidly transfer this compound across their cell membranes. More surprising was the almost equal ability of cells grown with either tri- or diethanolamine to oxidize triethanolamine $N$-oxide; indeed, the specific activity of triethanolamine- $N$-oxide dehydroxyethylase in diethanolamine-grown cells, which have no obvious need for this enzyme, was not significantly different from its specific activity in triethanolamine-grown cells, where it is required. This could indicate that this enzyme is product-induced, by no means a novel situation in catabolic pathways, two of the earliest instances of this phenomenon being the product induction by L-kynurenine in the pathway of L-tryptophan degradation in Pseudomonas fluorescens (Palleroni \& Stanier, 1964) and the induction of catechol-1,2-dioxygenase by the reaction product cis,cis-muconic acid in Pseudomonas putida (Ornston, 1966). The specific activity of the diethanolamine oxidase system is also high in both di- and triethanolamine-grown cells, as would be expected, yet diethanolamine is poorly oxidized by whole cells grown with triethanolamine. Presumably this is due to a 'permeability problem' and suggests that some system is responsible for transporting diethanolamine into the organism and that this is only present when the cells have become acclimated to this compound.

Thus, in any formulation (cutting fluids or whatever) that contains di- or triethanolamine these compounds are potentially readily biodegradable. Such formulations could become infected with microbes capable of degrading these substances unless an addition is made to the formulation to prevent this occurring.

G.R.W. is grateful to the Science Research Council for a CASE award. He and A.G.C. would like to thank Shell Research Ltd for their interest and additional financial assistance in this work and in particular Dr P. Burkhill (Shell Research Ltd, Thornton Research Centre) and Mr E. C. Hill (Microbiology Department, University College, Cardiff) for their advice about cutting fluids. 


\section{REFERENCES}

Blackwell, C. M., Scarlett, F. A. \& Turner, J. M. (1976). Ethanolamine catabolism by bacteria, including Escherichia coli. Biochemical Society Transactions 4, 495-497.

BRADBEER, C. (1965). The clostridial fermentations of choline and ethanolamine, I. Journal of Biological Chemistry 240, 4669-4674.

ByRne, G. A. (1965). The separation of 2,4 dinitrophenylhydrazones by thin layer chromatography. Journal of Chromatography 20, 528-539.

Colby, J. \& ZatMan, L. J. (1971). The purification and properties of a bacterial trimethylamine dehydrogenase. Biochemical Journal 121, 9p-10p.

Colby, J. \& Zatman, L. J. (1973). Trimethylamine metabolism in obligate and facultative methylotrophs. Biochemical Journal 132, 101-112.

Colby, J. \& Zatman, L. J. (1974). Purification and properties of the trimethylamine dehydrogenase of bacterium 4B6. Biochemical Journal 143, 555-567.

CRIPPS, R. E. \& Noble, A. S. (1973). The metabolism of nitrilotriacetate by a pseudomonad. Biochemical Journal 136, 1059-1068.

Dagley, S. \& Gibson, D. J. (1965). The bacterial degradation of catechol. Biochemical Journal 95. 466-474.

Dixon, G. H. \& Kornberg, H. L. (1959). Assay methods for enzymes of the glyoxylate cycle. Biochemical Journal 72, 3P.

EADY, R. R., JaRman, T. P. \& LARge, P. J. (1971). Microbial oxidation of amines. Partial purification of a mixed-function secondary-amine oxidase system from Pseudomonas aminovorans that contains an enzymically active cytochrome-P-420-type haemoprotein. Biochemical Journal 125, 449-459.

GotTo, A. M. \& Kornberg, H. L. (1961). Properties of a glycerate-forming enzyme from Pseudomonas ovalis Chester. Biochemical Journal 79, 9P.

Jones, A. \& Turner, J. M. (1971). Microbial metabolism of amino alcohols via aldehydes. Journal of General Microbiology 67, 379-381.

Jones, A. \& TURNER, J. M. (1973). Microbial metabolism of amino alcohols. 1-Aminopropan-2-ol and ethanolamine metabolism via propionaldehyde and acetaldehyde in a species of Pseudomonas. Biochemical Journal 134, 167-182.

Kaplan, B. H. \& Stadtman, E. R. (1971). Ethanolamine deaminase (Clostridium sp.). Methods in Enzymology 17B, 818-824.
Krakow, G. \& Barkulis, S. S. (1956). Conversion of glyoxylate to hydroxypyruvate by extracts of Escherichia coli. Biochimica et biophysica acta 21, 593-594.

LARGE, P. J. (1971). The oxidative cleavage of alkyl-nitrogen bonds in microorganisms. Xenobiotica $1,457-467$.

MeiberG, J. B. M. \& Harder, W. (1979). Dimethylamine dehydrogenase from Hyphomicrobium X: purification and some properties of a new enzyme that oxidizes secondary amines. Journal of General Microbiology 115, 49-58.

Meiberg, J. B. M., Bruinenberg, P. M. \& Harder, W. (1980). Effect of dissolved oxygen tension on the metabolism of methylated amines in Hyphomicrobium $\mathrm{X}$ in the absence and presence of nitrate: evidence for 'aerobic' denitrification. Journal of General Microbiology 120, 453-463.

Myers, P. A. \& Zatman, L. J. (1971). The metabolism of trimethylamine- $N$-oxide by Bacillus PM6. Biochemical Journal 121, 10P.

NARROD, S. A. \& JAKOBY, W. B. (1964). Metabolism of ethanolamine - an ethanolamine oxidase. Journal of Biological Chemistry 239, 2189-2193.

Newman, B. M. \& Cole, J. A. (1977). Lack of a regulatory function for glutamine synthetase protein in the synthesis of glutamate dehydrogenase and nitrite reductase in Escherichia coli K12. Journal of General Microbiology 98, 369-377.

ORNSTON, L. N. (1966). The conversion of catechol and protocatechuate to $\beta$-ketoadipate by Pseudomonas putida. IV. Regulation. Journal of Biological Chemistry 241, 3800-3810.

Palleroni, N. J. \& Stanier, R. Y. (1964). Regulatory mechanisms governing synthesis of the enzymes for tryptophan oxidation by Pseudomonas fluorescens. Journal of General Microbiology 35, 319-334.

Paz, M. A., Blumenfeld, O. O., Rojkind, M. Henson, E., Furfine, C. \& Gallop, P. M. (1965). Determination of carbonyl compounds with $\mathrm{N}$ methyl benzothiazolone hydrazone. Archives of Biochemistry and Biophysics 109, 548-559.

Scarlett, F. A. \& Turner, J. M. (1976). Microbial metabolism of amino alcohols. Ethanolamine catabolism mediated by coenzyme $B_{12}$-dependent ethanolamine ammonia-lyase in Escherichia coli and Klebsiella aerogenes. Journal of General Microbiology 95, 173-176. 